\title{
SEXUAL VIOLENCE AND THE MENTAL HEALTH SYSTEM: A CRITICAL DISCOURSE ANALYSIS
}

\author{
by \\ Julia Getchell, BSW, McMaster University, 2018
}

\author{
An MRP \\ presented to Ryerson University \\ in partial fulfillment of the \\ requirements for the degree of \\ Master of Social Work \\ in the Program of \\ Social Work
}

Toronto, Ontario, Canada, 2019

(C) Julia Getchell 2019 


\section{AUTHOR'S DECLARATION FOR ELECTRONIC SUBMISSION OF A MRP}

I hereby declare that I am the sole author of this MRP. This is a true copy of the MRP, including any required final revisions.

I authorize Ryerson University to lend this MRP to other institutions or individuals for the purpose of scholarly research

I further authorize Ryerson University to reproduce this MRP by photocopying or by other means, in total or in part, at the request of other institutions or individuals for the purpose of scholarly research.

I understand that my MRP may be made electronically available to the public. 


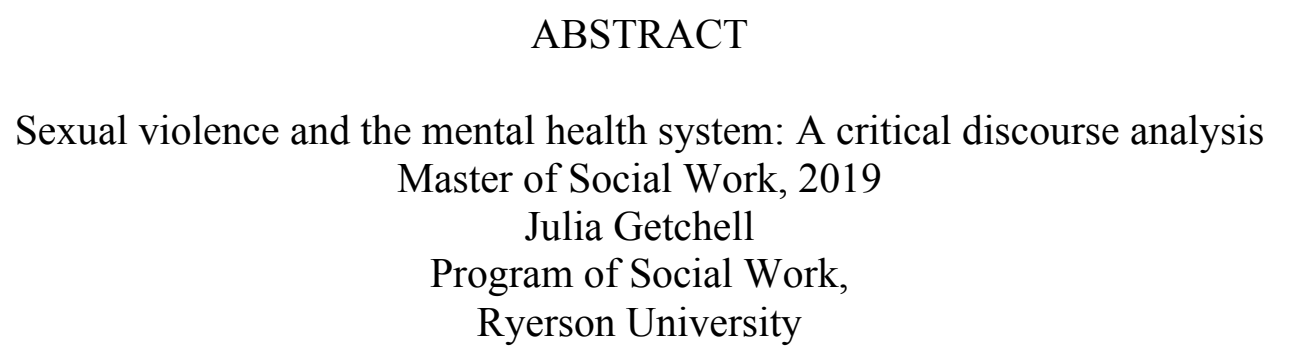

Sexual violence is a relevant topic in the Canadian mental health system. However, the dominant bio-medical understanding of mental health can be harmful to survivors. This study is focused on analyzing how sexual violence is discussed within the bio-medical mental health system. The bio-medical understanding of mental health is one that conceptualizes "mental illness" as brain disease and emphasizes pharmacological treatment. Sexual violence is a broad term that describes any violence, physical or psychological, carried out through sexual means or by targeting sexuality. Critical Discourse Analysis is used in this study to find and analyze discourses in the bio-medical mental health system found in three interviews with mental health service providers. The discourses that emerged were as follows: 1. people were "boiled down" to their diagnoses or experiences of sexual violence; 2. professionalism; 3 . being funneled into "streams of care"; 4. what makes someone credible; and 5. who "gets it". The MRP concludes with a discussion of implications of these findings for social work. 


\section{ACKNOWLEDGEMENTS}

Thank you to my supervisor Samantha Wehbi for making time to meet with me throughout this process, keeping me on track with ambitious timelines, and always having chocolate. Thanks to my parents and pseudo-parents for housing me and supporting me while I ran around all over the place. Special thanks to Julian for reading through my whole rough draft until 4am, you are amazingly supportive and I am lucky to have you. Thanks to my best friends and study partners for keeping me company through the days that seemed to last forever. Jessie, Shaila, Gemma, Maddie, Amanda, Anna, Bronwyn, you all inspire me with your big brains and hearts. Thanks to my team at placement for understanding the life of a student and not adding more stress to my plate. You have the healthiest work culture I have ever experienced and I'm thankful for the lesson on being gentle with myself. 


\section{DEDICATION}

To all the people going through it and to all those who've shared their stories with me throughout the years. 


\section{TABLE OF CONTENTS}

Chapter 1: Introduction

Page \#1

Chapter 2: Literature Review and Theoretical Framework

Page \#6

Chapter 3: Methodology

Page \#15

Chapter 4: Findings

Page \#21

Chapter 5: Discussion

Page \#43

Appendices

Page \#53

Reference List

Page \#59 


\section{LIST OF APPENDICES}

Appendix A - Recruitment Poster

Appendix B - Recruitment Email

Appendix C - Interview Questions

Appendix D - Ethics Approval
Page \# 53

Page \# 54

Page \# 56

Page \# 57 


\section{CHAPTER 1. INTRODUCTION}

To write this Major Research Paper (MRP) I interviewed three mental health service providers. I then analyzed the discourses that emerged in the interviews in relation to my theoretical frameworks using Critical Discourse Analysis (CDA). The definition of the mental health system that I used for this paper was broad and included any workplace that had a biomedical understanding of mental health. Therefore, when recruiting, the participant's workplaces did not necessarily need to be services completely dedicated to mental health services, but they had to work with psychiatrized people in some way. My methodological framework focuses on discourses because I think that the ways something is discussed can be indicative of the ways a system impacts the people who interact with it. One of oldest principles of the medical establishment is to do no harm (Attfield, 2001). However, I argue that the bio-medical understanding of mental health does just that to survivors of sexual violence.

Starting this MRP, I believe that trigger warnings are important. Gerdes (2018) describes trigger warnings as "an accessibility practice developed by and for survivors of trauma" (p.5). Therefore, in order to make this paper more accessible, I will outline the topics that may be triggering to readers. In this paper, there are discussions of sexual violence, medical and pathologizing language used to describe mental health, ableism, suicide, child apprehension, intimate partner violence, forced hospitalization and lack of adequate support services. There are no detailed descriptions of assault or abuse. Most of the direct quotes come from service providers' experiences. Sometimes they have quoted what clients have said to them about their experiences accessing services. In the literature review there is a discussion about how academic 
scholarship promotes harmful ideas about sexual violence and mental health. Direct quotes from service providers are in the "findings" section.

In this paper, I refer to people who have experienced sexual violence as "survivors" at times. I understand that language is important and there are many ways that people refer to themselves. For example, the terms "victim" and "survivor" are often contested in terms of which is most appropriate (Williamson \& Serna, 2018). "Victim" is the term most often used by the legal and medical systems, while "survivor" has been more widely used by advocacy groups (2018). However, I recognize that both terms have issues because "victim" can be blaming and infer that the person is weak and "survivor" can imply that they must be strong or actively healing from their experiences. Both can put pressure on individuals to respond to violence in a specific way. Many folks who experience sexual violence choose not to use any labels for this reason. Therefore, in this paper I refer to them as "people who have experienced sexual violence" or "survivors." I use this language as a way of acknowledging that people use different terms to define themselves and their experiences and that all of the ways they do so are valid. I also use the term "survivor" in some cases as an acknowledgement to the advocacy work that has been done in order to resist the pathologization of sexual violence.

In this paper I define sexual violence as a broad term that describes any violence, physical or psychological, carried out through sexual means or by targeting sexuality. Sexual violence is understood in this project to not be a series of unconnected incidents, but as a system of power. The Pennsylvania Coalition Against Rape mentions in their publication on poverty and sexual violence that:

There are many definitions of sexual violence in our society, all of which are influenced by social, economic, political, and cultural forces and perspectives. The rape crisis 
movement has strived to define sexual violence comprehensively and from the perspectives of victims and survivors while acknowledging that individuals define and experience sexual violence in unique ways. (Greco \& Dawgert, 2007, p.2)

I am using this definition because of its broadness and acknowledgement of how systems and structures contribute to sexual violence. In this paper I chose to examine how sexual violence is discussed in the bio-medical mental health system specifically because I have experiences working and volunteering in the mental health system and in a sexual assault centre. The title of this paper is Sexual Violence and the Mental Health System because, while I recognize that the mental health system uses more than just the bio-medical model, in my experience, it is the predominant form of understanding mental health in Canada's large mental health establishments.

Moreover, I am concerned with the pervasive understanding of mental health that holds power to control the way people are able to access services. Therefore, I am less interested in examining services that do not fit the dominant perspective. In the roles I occupied in mental health and sexual assault services, I found that sexual violence was discussed in very different ways depending on the environment. I am interested to see how these varying discourses affect the quality of services that people access. I define the bio-medical understanding of mental health based on Deacon's (2013) definition that "The biomedical model posits that mental disorders are brain diseases and emphasizes pharmacological treatment to target presumed biological abnormalities" (p.846). Many places often work from this standpoint, including hospitals, ACT Teams, group homes and shelters. The bio-medical model is not the exception, but rather the norm in Canadian society for defining mental health and is widespread throughout many services. 


\section{Context}

Discourses of sexual violence in the mental health system are very important for me to disrupt because I have experienced working in this system first hand. I wanted to talk to more professionals in this field in order to document their experiences. I think that in order to change an issue, it must first be recognized as such. It's also an opportunity for me to do more research into a topic that I think is very relevant and expansive. Moreover, sexual violence has been receiving increased coverage in the news in the past few years. It is a very timely topic that has gained mainstream attention because of the "Me Too" movement that was started by Black activist Tarana Burke in 2006, and went viral on the internet in 2017 (Rodino-Colocino, 2018). I feel that this increased attention to the issue is an opportunity to push the understanding of sexual violence further and connect it to other systems of oppression. Sexual violence can then be connected to the unquestioned discourses found in powerful social service institutions. Calling some of these discourses into question is the main focus of this paper. Burke says "No matter how much I keep talking about power and privilege, they [media in coverage of \#MeToo] keep bringing it back to individuals ... It defeats the purpose to not have those folks centered-I'm talking black and brown girls, queer folks" $(2018$, p.98). Therefore, it is important that in this study I make it clear that sexual violence is a systemic issue that is perpetuated by systems of power and control including sexism, white supremacy, and in the context of this study I focus on its connection to sanism. Anti-Black sanism scholars define sanism as a form of oppression that "makes normal the practice of discrimination, rejection, silencing, exclusion, low expectations, incarceration, and other forms of violence against people who are othered through mental 'illness' diagnosis, history, or even suspicion” (Meerai, Abdillahi, Poole, 2016). This study is very contemporarily relevant and is meant to not only question the way mainstream society treats 
the topic of sexual violence, but specifically the way the bio-medical mental health system reinforces these harmful ideas. 


\section{CHAPTER 2. LITERATURE REVIEW \& THEORETICAL FRAMEWORK}

My Major Research Paper is focused on analyzing the discourses of sexual violence within the bio-medical mental health system. In order to find literature on this topic, I searched for articles that touched on the intersections between mental health services and sexual violence. I found three main themes in the literature: the impacts of sexual violence on survivors' mental health, disclosure patterns, and how survivors interact with various systems (including the mental health system). Two well-cited, older articles also discussed mental health workers' training, which I have chosen to include due to their relevance for my particular research. Some articles are included in multiple themes because of the overlap between how survivors interact with systems and who they disclose to. In order to keep focused on my topic, I only included articles that had some connection to both the mental health system and sexual violence.

\section{Impacts of Sexual Violence}

Many of the articles I examined in my literature review focus on the impacts of sexual violence on survivors' mental health. Bryant-Davis, Ulman, Tsong, Tillman \& Smith, 2010; Eisenberg, Lust, Hannan \& Porta, 2016; Gomez \& Freyd, 2017; Sigurvinsdottir \& Ullman, 2016; Temple, Weston, Rodriguez \& Marshall, 2007). For example, Eisenberg, Lust, Hannan and Porta's article (2016) talks about how following a sexual assault it is common to experience emotional distress, depression, anxiety, and increased attempts of suicide. However, the focus on impacts is problematic because it treats outcomes as more important than processes and fails to challenge larger systems, like rape culture, that contribute to sexual violence. It is also very individualistic to only focus on people's mental health without talking about the systems that affect people's wellbeing. Individual focus is a colonized approach that is contradictory to 
Indigenous understandings of wellbeing that focus on the complex interplay between spirituality, physical status, cognitive and emotional processes, and environments (Hodge, Limb \& Cross, 2009). Moreover, impacts of sexual violence on mental health as a theme plays into the positivist paradigm of research because it focuses on discovering a "truth" about survivors' experiences. Positivism is a stance that the "truth" about the world is observable, quantifiable, and exists separate from human perception (Holtz \& Odağ, 2018). From a positivist standpoint, the truth can therefore be observed in objective ways (2018). Positivism is endorsed by quantitative methods (2018).

Three of the articles in the literature review that focused on mental health outcomes were quantitative surveys (Bryant-Davis, Ulman, Tsong, Tillman \& Smith, 2010; Eisenberg, Lust, Hannan \& Porta, 2016; Gomez \& Freyd, 2017). The fourth was conducted through an interview process (Temple, Weston, Rodriguez \& Marshall, 2007). However, all of these articles have a distinctive focus on individual outcomes. Two articles in this thematic group talked about intersectional issues (Bryant-Davis, Ulman, Tsong, Tillman \& Smith, 2010; Sigurvinsdottir \& Ullman, 2016). One study found that poverty was positively associated with Post Traumatic Stress Disorder (PTSD), depression and drug use among African American women survivors (Bryant-Davis, Ulman, Tsong, Tillman \& Smith, 2010). Another study found that race on its own was not a predictor of higher PTSD or depression, but Black bisexual women were the group most likely to experience these impacts (Sigurvinsdottir \& Ullman, 2016). In a study that focused on university students' mental health and services following sexual assault, $80 \%$ of the respondents were white, but this was not discussed as a limitation (Eisenberg, Lust, Hannan \& Porta, 2016). Eisenberg, Lust, Hannan and Porta's study shows evidence of assimilationist 
epistemology of race because the dominant group is seen as a normative and unquestioned authority of knowledge (Hunter, 2002).

\section{Disclosure Patterns}

Many of the articles that I found about sexual violence had a heavy focus on disclosure patterns (Ahrens, Stansell \& Jennings, 2010; Jackson, Valentine, Woodward \& Pantalone, 2017; Patterson, Greeson \& Campbell, 2009; Starzynski \& Ullman, 2014). Disclosure patterns are about who survivors tell their experiences to, whether it is friends, family, or professionals. It also relates to how many times people talk about their experiences of sexual assault, if at all. While this knowledge is important in order to identify gaps in services, the focus on disclosure puts the responsibility on the survivor to address their own experiences, instead of focusing on how to prevent sexual violence in the first place. These articles fail to address the ways sexual violence is created and maintained through systems of oppression. They instead focus on how to address sexual violence after it happens by looking at the ways survivors are doing this work for themselves. It is dangerous to focus on disclosure because it paints some people as deserving or not deserving of services based on something that the authors or service providers perceive to be better behaviour. For example, one article found that delayed disclosure was positively associated with poor mental health (Ahrens, Stansell \& Jennings, 2010). In practice, this information could contribute to survivors being blamed for their own "poor mental health" if they delay disclosing. The article also fails to account for the complex reasons why some survivors choose to delay disclosure. Other articles found that out of all professionals, survivors were most likely to disclose to mental health professionals (Jackson, Valentine, Woodward \& Pantalone, 2017; Ullman, Filipas \& 2001). Identifying the high use of mental health services 
demonstrates a clear need for mental health professionals to be knowledgeable about how to support people who disclose experiences of sexual violence.

\section{Interactions with Various Systems}

Similar to the idea of disclosure, many articles on the topic of sexual assault and mental health specifically focus on how survivors interact with various systems (Ahrens, Stansell \& Jennings, 2010; Eisenberg, Lust, Hannan \& Porta, 2016; Jackson, Valentine, Woodward \& Pantalone, 2017; Patterson, Greeson \& Campbell, 2009; Simmel, Postmus \& Lee, 2016; Starzynski \& Ullman, 2014). For these articles, the most common systems mentioned in relation to sexual assault were the legal system, the medical system, the mental health system, and rape crisis centres. For example, one study found that survivors rated tangible services as more helpful than therapeutic services (Simmel, Postmus \& Lee, 2016) and another found that women who disclosed to mental health services were more likely to be white, educated and have higher incomes (Starzynski \& Ullman, 2014).

Understanding how survivors interact with systems is important in order to identify possible barriers and ways to improve these services. It is also interesting to think about why a more privileged group of survivors is more likely to disclose to mental health services. Their increased disclosure could have to do with their ability to access certain services and perhaps the greater belief that they will receive a positive reaction to their story. For example, one barrier described in the scholarship for accessing services was that both non-disclosure and negative social reaction were related to more symptoms of depression and post-traumatic stress (Ahrens, Stansell \& Jennings, 2010). Therefore, survivors are put in a difficult position if they suspect a negative reaction, whether to disclose or not, because either one will have negative implications. 


\section{Worker Knowledge and Training}

Articles that focus on worker knowledge and training are particularly applicable for my research. For my MRP I want to discover what discourses are present about sexual violence in the mainstream mental health system in order to identify gaps in service. One issue that I came across was that the two articles that focused on service providers' knowledge were both relatively old articles (Campbell \& Raja, 1999; Campbell, Raja \& Grining, 1999). However, the findings of these articles were alarming. For example, $14 \%$ of service providers in one study (58\% MSWs) had no formal training on gender-based violence (Campbell, Raja \&

Grining,1999). Of these $14 \%, 43 \%$ of them had worked with survivors of sexual assault (Campbell, Raja \& Grining,1999). The other study found that many survivors experienced secondary victimization from receiving poor services from the mental health system (Campbell \& Raja, 1999).

Ahrens, Stansell \& Jennings recommend that trainings for rape crisis centres, campus prevention programming, and professional services should talk about disclosure patterns and that comprehensive training could help alleviate unnecessary distress for people if they do decide to disclose (2010). In their study they found that negative reactions to disclosures of sexual violence caused increased depression and post-traumatic stress (2010). Therefore, they identified that worker training is important not just in order to support people who have disclosed instances of sexual violence, but also to avoid doing further harm. 


\section{Limitations of the Scholarship}

The studies used for this literature review often lacked participants' voices. Though some studies included quotes from participants (Jackson, Valentine, Woodward \& Pantalone, 2017; Patterson, Greeson \& Campbell, 2009) this was rare. Articles that incorporated participants' voices found a way to resist the notion that knowledge is produced through and by professionals. However, the majority of the studies were entirely written from the standpoint of the researchers without any voice given to the participants whatsoever. Furthermore, none of the researchers situate themselves in the studies, which reinforces the idea that they are "objective." The studies found on my MRP topic are largely centred around positivist or pragmatic frameworks. For example, studies that are focused on the ways survivors react to sexual violence are mostly based in positivism because of their focus on finding out a "truth" about the ways survivors cope and react to a life event.

The use of surveys also indicates that these articles use a positivist framework. Surveys are common among positivist researchers and not for interpretive researchers (Neuman, 2006). Interpretive researchers believe that the way each individual interprets the survey will affect the findings, and therefore, surveys lack necessary context (2006). Many of the studies also have over a hundred participants (Bryant-Davis, Ulman, Tsong, Tillman \& Smith, 2010; Campbell, Raja \& Grining,1999; Campbell \& Raja, 1999; Eisenberg, Lust, Hannan \& Porta, 2016; Gomez \& Freyd, 2017; Sigurvinsdottir \& Ullman, 2016; Simmel, Postmus \& Lee, 2016; Starzynski \& Ullman, 2014; Temple, Weston, Rodriguez \& Marshall, 2007). The number of participants shows an emphasis on trying to ensure that the research is generalizable and has an ability to expose "truths" about the human condition. In this research paper I also need to resist the urge to 
find "truths" about the mental health system. I aim to instead talk about the specific discourses that I found while conducting the interviews.

Some of the studies focus on pragmatic frameworks because they center findings that are useful to assist practice decisions (Grey, Plath \&Webb, 2009). I find myself drawn to a pragmatist framework because I want to see how research can be used to change systems and improve services. However, pragmatism also has issues because it has a focus on outcome instead of process. One example of pragmatic thinking in the literature is when articles focus on "how survivors interact with services," which is applied to improve the quality of those services. This is seen in Patterson, Greeson, and Campbell's (2009) article because they specifically focus on why survivors did not access services in order to better understand how to make them more accessible. Critical Discourse Analysis draws partially from pragmatism in that it is "problem oriented" (Wodak \& Meyer, 2009). It is also interpretive because it focuses on analyzing discourse in a way that embraces the subjectivity of the researcher and does not look for universal truths (2009).

Though there is some pragmatic influence in the literature, the majority is based in positivism. There are limitations to positivist research because it reduces complex human experiences into quantifiable variables (Grey, Plath \& Webb, 2009). Positivism also does not recognize or address the influence of epistemology (Hunter, 2002). Epistemology is the theory of knowledge and justification (Audi, 2003). In other words, it is about how people know what they know. Positivism relies on a scientific neutrality that is challenged by the epistemological tradition of scepticism (Williams, 2001). One strength of positivism is its robustness of evidence (Grey, Plath \& Webb, 2009). I argue, however, that evidence is not neutral or true, no matter how something is studied. Even so, positivism has the support of universities and is considered 
the "gold standard" for research (Grey, Plath \& Webb, 2009). Therefore, although the research is not as rich or interesting, it has the ability to be taken seriously, be published, and ultimately draw greater attention to important issues such as sexual violence. This Major Research Paper is not focused on pragmatism or positivism. The small sample size makes it unable to reach any conclusions about the experience of being a practitioner working within the mental health system and encountering a survivor of sexual violence. It is more meant to explore some of the discourses that are present in that system based on the experience of practitioners. However, the study is not about individuals. Instead, I try to draw attention to the bio-medical mental health system and the way it operates to maintain power structures. Based on the findings from the literature review and in an attempt to address gaps, my research focuses on the following research question: What are the discourses of sexual violence within the bio-medical mental health system and how might they contribute to systemic injustices that survivors face?

\section{Theoretical Frameworks}

This research is inspired and informed by the literature of Mad and feminist scholarship and social movements. Specifically, I situate sexual violence in the context of patriarchy and utilizing theories of sanism and epistemic violence to discuss the ways in which this topic is taken up by psy professionals, including social workers. I interviewed service providers in order to take the responsibility off of survivors and also to value the ways that service providers can resist psy discourses while simultaneously being complicit in these systems. I value the input of service providers and wanted to give them an opportunity to resist these narratives within their workplaces. In the interviews there were both instances of resistance and complicity that I deconstruct in the discussion chapter. In their article, Rimke says "Psychocentrism largely rests 
upon the epistemological prestige of positivism" (2016, p.8). Critiquing the ways sexual violence is discussed within the mental health system is a way to challenge psychocentrism and, by extension, the positivist ways people are treated within these systems. In this study I discuss concepts that are anti-capitalist, anti-sanist, feminist, anti-racist and anti-colonial. By using scholarship from these standpoints I hope to provide a critique of the bio-medical mental health system and the ways in which it operates to oppress survivors of sexual violence. For example, in the literature and in the interviews I conducted there were mentions of how the bio-medical model simplifies people's experiences and de-humanizes them.

I use critical theories in order to resist this dehumanization and work towards social justice while also acknowledging my own privileges and complicities within the system. Diamond (2013) describes the anti-sanist movement as having three main constituencies. The first constituency is psychiatric survivors, a group with a history of resisting the medical treatment of folks labelled "mentally ill" (2013). The Mad constituency grew out of the psychiatric survivor movement, but is more focused on celebrating Mad experiences instead of focusing solely on psychiatric oppressions (2013). Lastly, they identify the third constituency as anti-psychiatry, which is an academic constituency made up of folks who may or may not have lived experience with psychiatrization, but are critical of the medical system (2013). I situate this study as part of the third constituency, and hope that it will build on the existing scholarship that challenges the ways psychiatrized people are mistreated in the bio-medical mental health system, while adding an additional lens focused on the experiences of survivors of sexual violence. 


\section{CHAPTER 3. METHODOLOGY}

For my Major Research Paper, I used Critical Discourse Analysis (CDA). CDA is problem-oriented and interested in demystifying ideologies and power in society (Wodak \& Meyer, 2009). It uses language as a point of study in order to look at power in the theoretical tradition of Foucault. I think that this methodology is extremely useful for my study because I am interested in how discourses of sexual violence in the bio-medical mental health system reproduce systems of power and control such as sanism and sexism. Moreover, I think that when trying to change systems to be more equitable and serve marginalized communities, it is important to deconstruct systems of violence in order to understand and subvert them. Therefore, my main goal in this research is to be able to utilize a methodological approach that allows me to challenge systems of oppression and violence within the mental health system, specifically in regards to sexual assault survivors.

CDA asks the question "what is valid knowledge?" (Wodak \& Meyer, 2009, p.34). I find that this fits extremely well with my theoretical framework, specifically the idea of epistemic violence. Those who study epistemic violence, a concept that grew out of post-colonial scholarship, are concerned with the ways that certain knowledges and ways of being in the world are devalued or seen as illegitimate (Liegghio, 2013). This type of violence is often perpetuated towards psychiatrized individuals who access the mental health system (2013). Therefore, it is important to question what valid knowledge is in order to avoid re-creating systems of violence and control in my research. I see CDA as a methodology that can help to keep me accountable to my theoretical frameworks and goals by raising questions about the ways knowledge is validated through various systems of power. For example, what systems in society validate the knowledge of the professionals whom I interview and why? How do these mental health professionals' 
experiences of supporting survivors of sexual violence translate into knowledge about the ways dominant systems operate?

One aspect of CDA is that researchers make their positions explicit (Wodak \& Meyer, 2009). It is important to me as someone trying to do work that is committed to social justice and systemic change to be explicit about my biases. The idea that researchers must be "objective" is rooted in positivist epistemology that reinforces dominant ideas about power in society.

Therefore, the theories and methodology that I am using explicitly come from a standpoint that is rooted in anti-racism/anti-oppression and supports anti-psychiatric and feminist movements. Since CDA researchers make their positions explicit, I also position myself within the research as someone who has a lot of power. I come at the research primarily as a service provider with experience in the mental health and sexual violence sectors. Moreover, I must be explicit about the ways that I interact in interviews with professionals as a white woman, a social location that dominates social work practice and its history of colonialism. My knowledge within the mental health system has been validated in problematic ways that deny the validity of Indigenous and Mad epistemologies. This also applies to the people I interviewed as they are all professionals who have been given power by the mental health system. Using CDA, I critique not only the idea of objectivity, but also how my subjective knowledges and questions have been validated in a system of academic colonialism.

CDA uses sampling that mostly relies on "typical texts" (Wodak \& Meyer, 2009, p.23). This fits with my study because I interviewed professionals in the bio-medical mental health system. I focused specifically on the bio-medical model because it is the dominant way that mental health is seen in Canada and holds a lot of power on an individual and societal level. It holds power on an individual level because it acts as a rationale to control psychiatrized people's 
bodies, for example by way of forced medication adherence. One study that focused on youth's adherence to psychotropic medication found that of those who participated $63 \%$ would discontinue use when they reached adulthood and $44 \%$ of participants felt that they were forced into taking the medication (Moses, 2011). The bio-medical mental health system also holds societal control in that it shapes the types of services that are accessible to folks. The result is psychocentrism which Rimke describes as "a form of social injustice, where individual reformation rather than social and economic justice is promoted" (Rimke, 2016, p.5).

\section{Recruitment and Interview Style}

For my study I relied upon primary sources of inquiry in the form of individual interviews with service providers in the bio-medical mental health system. While Critical Discourse Analysis is often done using secondary sources, I decided to use primary sources because I could not find any documents to analyze that specifically focus on sexual violence from the perspective of the bio-medical mental health system. The lack of information available largely has to do with the fact that the issue seems to be erased within this system despite the prevalence of survivors accessing mental health services. I also think that it was interesting to interview service providers because they had insight into bio-medical discourses and things that go on within that system that are less apparent in public-facing documents. It makes sense that psy discourses would be present in documents put out by bio-medical mental health institutions. However, I feel like any document that would be accessible to me as a public citizen has been filtered in a way that a private conversation between professionals would not be. Therefore, I think that individual interviews created a more accurate picture of the sexual violence discourses within the bio-medical mental health system. 
For my recruitment I accessed my personal networks because I have had professional contact with the mental health and sexual violence sectors in the past. Accessing these networks also means that the people who received my recruitment materials were in some way familiar with me and the work that I have done. I think that this was important because sexual violence is a difficult subject to discuss with a complete stranger. I also included on my consent form that the study was more interested in studying trends and general discourses than how individual practitioners work or their specific stories. The focus on systems instead of individuals was strategic in order to make participants feel more comfortable with sharing and to protect their confidentiality.

I decided to do individual interviews instead of in groups to ensure the confidentiality of my participants. I wanted participants to be able to be critical of their organizations without the potential repercussions of other professionals listening to them. I also used audio recording in order to analyze my conversations in-depth and identify the bio-medical themes and discourses. I then analyzed them from a critical standpoint that is informed by theories about power and oppression. One of the reasons that I used CDA is because of its emphasis on authors being able to express their viewpoints. My past experiences working in the mental health system have lead me to believe that the bio-medical model is extremely harmful and contributes to the mistreatment and lack of autonomy given to psychiatrized individuals. Moreover, this is even more harmful when applied to survivors of sexual violence because of the devaluation of their stories and the additional systemic injustices they experience. 


\section{Participants}

The individuals whom I have recruited come from different backgrounds within the biomedical mental health framework. I think it is important that I recruited people from different work backgrounds because it aligns more closely with the goal of this paper than if I were to recruit from the same organization or only similar contexts. I want to demonstrate how widespread the bio-medical understanding of mental health is and how it affects many areas of service provision. I, however, acknowledge that talking about all aspects of the mental health system is impossible with only three participants. I recruited participants using my personal and professional networks. The criteria for participation was that they needed to be a service provider who worked in the bio-medical mental health system and had experienced a disclosure of sexual violence in their place of work. Although it was not a requirement, all participants also had work experience in gender-based violence services as well.

In this paper, all of the participants are referred to using pseudonyms. The first participant, Terra, has worked in long-term care and violence against women shelters as a frontline service provider. Pauline works in a hospital outpatient mental health program, has worked for other mental health programs in the past, and a sexual assault center. Sarah has worked on a mental health crisis team in a hospital, an ACT team, various sexual assault services, domestic violence services, and in a hospital doing research. All three participants talked about working with psychiatrized people and experiencing disclosures of sexual violence in their workplaces. Since I focused on interviewing service providers, this research is a practice in "studying up," or studying those in powerful positions (Deliovsky, 2017). Though it was unintentional, all of the participants also had similar demographics in that they were all white-passing women. The 
white-privilege that the participants and myself have adds another layer of power to deconstruct through this process. 


\section{CHAPTER 4: FINDINGS}

In this chapter, I will go over prominent discourses that I have identified in the interviews. In order to look for discourses, I first analyzed metaphorical language in the transcripts. This is something that Jennifer Poole discussed in her book "Beyond the Rhetoric" in which she used Critical Discourse Analysis as a methodology (Poole, 2011). Using metaphor as a starting point, I then looked into the similarities in discourses and came up with categories to then discuss them.

\section{Boiled Down/ Chalked up}

Two metaphors that came up in the research were the idea of "boiling something down" or "chalking something up". These expressions both mean to make something less complicated than it actually is. These phrases were used by all three of the participants. Terra said that when she was working in long-term care that older adults" "identity becomes boiled down" to them being a victim if they have disclosed experiencing abuse. She said:

I find the way that conversation happens is that people who experience abuse, so older adults or even people in long-term care homes. They're portrayed solely as victims. It's like their identity becomes boiled down to just that. Like experiences of abuse. Like they are a body they're not a person.

Pauline talked about a strategy that she used when working with individuals diagnosed with borderline personality disorder (BPD). She would focus more abstractly on behaviours the people she worked with wanted to change instead of "boiling it down to diagnosis." She mentioned that she had received specific flow charts on how "emotions work and are reinforced specifically for people with BPD" and did not believe in treating someone's emotions around a 
diagnosis. She said:

A lot of the time we're like BPD... I have things people have given me of like, this is the flow chart of how emotions work and are reinforced specifically for people with the BPD. And I don't particularly like that it's like "this is for people with BPD" this is how you work kind of thing... I'm more so focused, like, abstractly on what's going on. Or like, "What behaviours do you find aren't working for you?" Or like, whatever, versus boiling it down to the diagnosis."

In both cases the person is "boiled down" or made to be defined by one thing instead of being seen as complicated. Sarah talked about people who she worked with as part of an Assertive Community Treatment (ACT) Team being called "weird" and this being "chalked up to" their mental health status without the team ever considering that they had experienced trauma. She said:

There's one person that I was seeing for a while and when I was on the ACT team. I mean, it to me, it's really clear that there's trauma. Like it's so obvious to me, that there's trauma. And then people are just "he's just weird" or like, "he just doesn't want to connect" or like, I don't know... the things that people like, sort of chalk it up to...

In all of the cases, the participants were referring to some kind of simplification. This manifested in the categorization of the person they were working with or their experiences in a simplistic way. They were seen only as their experiences with assault, or their diagnosis/mental health status. 
During the interviews there were many labels used to describe people. Some of these labels included specific diagnoses like schizophrenia, borderline personality disorder, dementia, developmental disability, cognitive impairment, anxiety, depression, bipolar, and "severe mental illness." These diagnoses are used commonly to describe people and their experiences in a way that allows them to be categorized and "treated" by the mental health system via the diagnostic and statistical manual (DSM). There are many critiques of the DSM. Hsu's (2019) article talks about Frantz Fanon's influential critique of the DSM as an anti-racist and anti-colonial psychiatrist and philosopher. Hsu states "Fanon's insights allow us to critique the colonizing force of the DSM-V in its tendency to isolate the notion of mental disorder from its full range of cultural, socio-economic, and political contexts" (p.55). Diagnosis can sometimes allow people to access helpful and specific services that they otherwise would not be able to receive (Eidse, 2018, June, 13). However, it can also have the effect of simplifying or essentializing people's experiences, which has been seen by the participants of this research. In her interview Pauline mentioned that:

Like some people are just not interested in medication. I think that psychiatry is helpful to some people and can really... (pause) Like it's based on diagnoses that problematize a lot of things. It kind of like... it sometimes makes the person the problem.

In all three interviews the participants talk about working with people who have "multiple diagnoses" or "comorbidity." Therefore, it seems that the people whom they work with are heavily diagnosed in order to access the services that they provide. This shows that in order to receive services, people are treated in a way that prioritizes diagnosis in order to make a plan for treatment. The focus on systematic treatment via diagnostic protocols, in my experience, can 
reduce the amount of autonomy and choice that someone is given over their own care plan.

\section{Professionalization}

Since this research is focused on systems and processes of the mental health system that do not appear to challenge sexual violence, I was very interested to talk with the participants about the training they have received by their workplaces. All three participants stated that they received no training about sexual violence from the mental health systems that they had worked within. Sarah mentioned:

There are definitely no protocols [about sexual violence]. The referral information is stuff that I've put together. It's nothing that anybody else gave me. Yeah, the agency did not prepare me at all. But to be fair, they didn't prepare me for anything. So I got there. And they're like, so you know, just do your own mental status exam. And I was like, what? So I had to, like research, the parts of a mental status exam and like... So now I have a form like, I made my own that I use.

I get the impression from this excerpt that a discourse of the mental health system is that employees are expected to already know about the topic. There is also a separation of the mental health system and sexual violence. Therefore, the training is different depending on what system you happen to work in, despite the two being interconnected. This was articulated by Terra when she said:

So like in long-term care you're taught to work with people who have mental illness and cognitive impairment. You're not taught how to work with people who've experienced sexual violence. And the shelter system a lot of the time it's the opposite, particularly 
because people who do have that kind of training they want really well paid positions in hospitals.

The idea is also present that people do not receive training because it is not seen as being necessary for their role. Terra talks about the nurse manager at the long-term care home providing informal support to people who have experienced sexual violence.

That is not part of the nurse manager's job description. Right? So um she was doing that on top of balancing like a hundred and twenty other things and she made a lot of time for this client and for like other people as well.

Sarah and Pauline also talked about training being focused on other topics. Sarah talks about how there is little training on mental health, let alone sexual violence within the hospital that she works at as a mental health crisis worker.

There's no training related to that [sexual violence] at all. The kind of training that is available is like, the ER [emergency room] doctors and stuff, like, we see all their training notifications. And they are being trained on like, you know, infant CPR. And whatever, like, has nothing to do with mental health at all. Right? And then for the mental health workers there's very little training.

Pauline mentioned that at the mental health hospital she works at, there is little practical training like how to support someone experiencing sexual violence. Instead the training seems to be focused on academic research related to the mental health field. She said:

At least what's been offered to me, I haven't had any specific training at the hospital on 
sexual violence. I feel like there's been nothing sticking out to me specifically.

Mainly, like, educational in terms of like research-based, so not really like a how-to.

Although she does think that it would be useful for staff to have more training on sexual violence. For example, she mentioned:

Someone who like is a clinician here, like, endorsed some of those [rape] myths. So like, yeah, I don't know if I recognized that right away. But like, that's definitely been something like, even I think that would be good training. Because we don't really know if we're endorsing this, unless we kind of like are confronted with that.

In the above excerpt Pauline mentions that training would be helpful in order to confront people with their own implicit endorsements of rape myths. I think it is important to point this out because in that sentence she implicitly acknowledged that the difference between her understanding and other clinicians' is that she has been confronted by her internalized rape culture through other work she has done. Therefore, it shows that a major factor in how clinicians think about sexual violence could be rooted in what they are (or are not) trained to think about it.

Terra mentions that part of the barriers to doing affective work in long-term care is understaffing. This shows that the issue is not just about how trained workers are, but also about their job constraints and time limits. She says “they gave people bonuses if they didn't report incidents." She also connects these policies to issues of funding saying "I think understaffing is because of funding." More so, the issue connects to larger systems of values and what type of work and lives are valued in society. She mentioned that: 
We don't value the kind of work that the people who work in long-term care homes do and we don't realize just how difficult that kind of work is. People don't want to work in these places. Um so I think like it's just a devaluation of the lives of people who have mental illness, or who have a cognitive impairment, or who have both, or who have a disability. Like very very marginalized people and particularly older women, right? Because the majority of people who tend to be older are women.

Terra also mentioned that the majority of support workers in long-term care are Black women. Therefore, we must also think about the devaluation of Black women's lives and how the work they do is difficult and often goes unrecognized. The whole topic of training and values of work in the mental health system goes back to a discourse around professionalization. For example, Sarah was expected to know all aspects of the job when she was hired for the crisis team because that was a standard expected of a professional. Pauline was surprised that "clinicians" supported rape myths because she ascribed to them a professional standard which she assumed would be in line with her own training and knowledge around sexual violence. Moreover, Terra saw in her workplace the devaluation of support work in long-term care because of the societal norm that does not see work done by Black women to be "professional". Despite this, she mentions that the Black women working at long-term care had a more competent understanding of sexual violence. She said:

They got it. I was really fortunate there in the sense that a lot of the staff even though they were nurses and doctors they all came from a specific framework. They also brought a kind of like common sense understanding. I think part of the thing is that these were women and a lot of them were women who were Black. So like they had been struggling 
against a lot of the same forces that their clients faced their entire lives. So they understood that this is not the best system.

Despite the understanding that people with lived experience have the ability to understand sexual violence and treat survivors with respect, a few times in the interviews, participants cited academic research as a way of explaining their understanding. Part of this could be, as Pauline mentioned partially because of the way social workers are trained to focus on "research-based" understandings. For example, Sarah talks about how people experience trauma differently by citing a psychologist who studied a plane crash and the experiences of different passengers on the same plane. Part of her understanding could also be that she worked in a research setting. She cites the connection to academia being helpful to her in her work and it being something that she finds is missing when working in a rural community. She says "but the problem is that you don't have the sort of academic, [in rural communities] like you don't have like teaching hospitals and stuff. Right? So I mean, that makes a difference to the quality, I think.” Therefore, academia is seen as something that works as a professionalizing force because in some contexts it is seen as a way to enhance quality of care. The professionalization of academia also shows how being "professional" is related to being powerful because both teaching hospitals and academia are powerful institutions that can affect trends in service provision.

\section{Streams of Care}

One discourse that came up a lot in the research was that there were different "streams" of care that people could access in the mental health system. Sarah mentioned:

I think that that being a crisis worker is like a really crucial spot, where you get kind of 
get funneled into a stream, right? So if somebody sort of funnels you into the wrong stream... Like if we've got you hooked up to see our crappy psychiatrist, and like, he's gonna put you on antipsychotics or whatever. You know what I mean? Like, it could be five years of like, the wrong stream, where you're not really getting any help. And then you're going to get side effects and... I mean, often, it's like depression and anxiety, whatever.

Sarah also mentioned that in her work there are three main streams that people tend to be funneled into: mental health, trauma, and addictions. This is really interesting to me because I see all of those things as being incredibly interrelated. She also mentioned that the consequences of going into the wrong stream can affect someone really seriously. For example, she said:

We have so many people that get end up getting like a diagnosis of like schizophrenia or something that are totally not schizophrenic like, it's totally, you know, dissociation and, or even just like voices that are sort of more trauma/personality disorder kind of voices, and they get labeled, with like schizophrenia, or whatever, and it's not schizophrenia. And medications for schizophrenia don't help.

This quote shows that people are getting diagnoses that are inappropriate. Schizophrenia is also considered a chronic condition (National Institute of Mental Health, 2016). Therefore, they will likely have the diagnosis for their entire lives. Sarah mentioned that they then receive medications for schizophrenia that do not work. Not having medication work can also put labels on people, for example if the doctor thinks that they are not taking them at all. Sarah said:

When I meet or hear about a patient like that a psychiatrist has been treating for many years, and they've tried every kind of anti-psychotic and it doesn't really help. To me, that's an 
indicator that you've got to look for the trauma. They need more counselling. Like it's more of a trauma issue, perhaps, right? But they don't, they just label them like they're either noncompliant, or they're just like, they have a, whatever they call it, like where it's... medication resistant. Or like, "they probably just don't work well with this medication.” It's like, well, there's a reason for that. Right?

Sarah's frustration with people being misdiagnosed and treated without considering trauma services shows how trauma can be misinterpreted in the bio-medical system because of the individual focus. Instead of thinking about a person's life as a whole, they are reduced to their biology or "abnormalities."

Something that also came up in the interviews was that sometimes service users needed to have a set of prerequisites before entering into a specific "stream." Specifically, Pauline talked about how at her workplace at $80 \%$ of the time the people she works with talk about sexual violence. She also talked about how the program was used as a starting point for people before they are accepted into another program specifically designed to deal with trauma. She said the program is "supposed to be kind of like a stabilization program, a lot of folks are referred for a discharge plan and are referred to the trauma specific services afterwards." Therefore, the discourse about "streams of care" also implies that trauma and mental health are different things and should be worked on separately. The discourse also emphasizes that people need to be at a certain stage in order to benefit from trauma services. Even though many people are interested in trauma services, less people are accepted into the program. For example, Pauline said:

What happens a lot of the time is that people want to go into like, some sort of treatment for sexual violence or trauma, and they either like started out or had their assessment and 
what's determined is that they're not able to do the program because they're not able to, like, manage all the stuff that's going to come up. Or that like they're increasing selfharm or suicidal thoughts, or something like that. And so they come here to do the program first to like, learn how to manage those things so that they are capable of really doing a deep dive into, like, exploring and processing trauma.

The separation of services into trauma services and mental health services, in this case delays or stops people's access to trauma services completely because of the expected behaviour of people in that program. However, if they need mental health services because of underlying trauma, restricting them from trauma services can deny people access to the help that they need.

People being able to access the services that they want to also has to do with the availability. For example, it is not just about being suitable for a program but also the accessibility of the program and whether or not what they need actually exists. For example, Sarah talked about how if a man has experienced sexual violence and wants to go into a trauma related program, there are not a lot of options. She mentioned:

I meet, so many men that have trauma. And, and I end up saying to them well if you were a woman, I'd be sending you here. But since you're not, I don't know where to send you. Right? Like, it's just really, very little. And also the other thing that, and I totally understand why this is, but the other thing that I find is a barrier is that the women's organizations that will accept men, they won't accept men if there's any question that that person may have been a perpetrator also.

This example shows that sometimes there are just no options for someone. Sarah is also a social worker in a rural community, so there are even less services. She mentioned that in the hospital 
she works there is not even a psychiatrist for people to see. There are unique challenges of living in a small town for people to access services without running into people that they know. For example:

Yup, and like, the small town-ness of it. So like, I remember talking to one person, and like, I had the perfect resource, right? I'm like, here's a resource. And he's like, nope, my ex-wife works there.

Another barrier for people to access the services that are best for them is having the money to pay for private services. Therefore, many people go into the public stream and get whatever services they can afford. Sarah mentioned in her interview that a lot of services are expensive and that is something she has to think about when funneling people into a stream. She said that:

I don't even bother recommending places that are expensive, right? Because, I mean, there's very few people, like unless somebody says, "money is not a problem, tell me who's the best" or whatever, then I would try and come up with something. But generally speaking, I just assume nobody has any money.

Pauline also talks about the inaccessibility of her work:

We don't have drop-in. So I mean, there's a few drop-in groups or whatever, but you really only know about them if you're like, already a part of the system and whatnot. Like, it's just not very accessible. Like, we don't really have a lot of late hour things or like weekend things.

Pauline's talk of accessibility also has to do with money because if there are not a lot of 
alternative hours, many people would not be able to work during the program. There is also an inaccessibility in the nature of working in a hospital in terms of people's comfort levels with accessing services from a large institution. For example, Pauline says:

I think there is like, for a lot of people who, who have experienced oppression in some form, I think there's, like, understandable fear, sometimes of huge organizations like this, that have been harmful to people in the past. And I think that keeps people away sometimes, and people feel more comfortable with, like, communitybased organizations.

Community-based organizations are also often under-funded (Canadian Mental Health Association, 2017, October, 19). This shows that even when people access public services, the well-funded hospitals are less accessible to people who are marginalized due to their inability to take time off of work and understandable lack of comfort with the medical establishment. If the mental health system is inaccessible to the most marginalized people in society then that leaves me to question what happens to those people. What comes to mind is that they are forced into the criminal justice system. In the discussion section of this paper, I further discuss the connection of psychiatrization, racialization, and criminalization.

\section{Credibility}

Part of accessing services also relates to the discourse of credibility. Some people are less likely to be believed about their experiences of sexual violence and therefore, less able to access appropriate services. This is related to forms of oppression that make someone more or less believable to the medical system. For example, Pauline talked about how people diagnosed with 
borderline personality disorder (BPD) are less believed. She said:

There's definitely a lot of stigma specific to like that diagnosis around like, "are they looking for attention?" Yeah, I think that's the main one. Are they like, attention seeking? Or like, lying?

Sarah also mentions this same stereotype about people diagnosed with BPD in her interview. She mentioned:

For some people, everything that comes out of the mouth of somebody with borderline personality disorder is probably lies, you know what I mean? Like, so... So yeah, "maybe it happened, but I'm sure she's making a bigger deal about it."

The quotes from Sarah and Pauline's interviews show that not all service users' words are taken in the same way. Specifically, both of them mentioned the diagnosis of borderline personality disorder. This interested me because it was not a diagnosis that I previously knew a lot about and they both mentioned it on their own without any prompts from me. I think it is important to focus on issues of credibility because they can be a sign that someone is experiencing epistemic violence in the mental health system.

BPD as a variable for credibility is based on a specific diagnosis imposed by the mental health system, not any particular behaviour. However, the participants also talked about behaviours that made people have difficulties accessing the mental health system in a way that was helpful to them. For example, Sarah mentioned her experience of a doctor being angry with a patient for "freaking out" during an internal gynecological exam. She said "The woman had like a flashback and the ER doctor was so angry about it.” She quoted the ER doctor saying 
“sexual assault, like, as if we all haven't had bad sex before." In that situation it was pretty clear that the ER doctor was treating the patient's experiences in a certain way because she was unhappy with her "freaking out". The situation outlines that there is a specific way to act in order to address trauma and "freaking out" is unacceptable. In Sarah's interview she talked about how reactions to trauma are unpredictable and that they are misunderstood a lot of the time if they do not fit into a specific idea that people have. She said "This girl could have a way bigger experience than you did from that right? Which is really hard for people to understand." The idea that people experience things differently is important for resisting sanism and validating people's experiences. Being dismissed is considered a natural reaction to socially unacceptable behaviour. This idea was also brought up in my interview with Terra as well. She described a client who was crying while she was working with her because she was scared of being in a situation that related to a traumatic instance of sexual violence that she had. For this person, the thought that she looked crazy made her feel ashamed. She described the experience of talking to the client by saying:

Well, this client told me you know like "I feel really ashamed of how I acted when I first met you." And I was like why is that? She's like "well, you know like I feel like you probably felt like I was a totally crazy person but this is why."

By focusing on the way that people act as a reason for their credibility, it marginalizes individuals who do not conform to the dominant power structures of white, cis, hetero supremacy. Specifically, in relation to sanism, only neuro-typical behaviour is seen as legitimate. Therefore, the idea of credibility must be discussed in relation to its relationship with power.

When thinking about credibility it is also important to note how gender affects this 
phenomenon. For example, in Terra's interview she talked about two separate instances where men were seen as being more credible. The first was when she described a story about a woman who was diagnosed with schizophrenia and bipolar disorder when she went to the hospital to try and access help dealing with gender-based violence. She stated that she was told:

My partner talked to the staff at the emergency department and convinced them that I was having a psychotic breakdown and instead of me getting support for being abused by my partner, instead what they did was put me in the mental inpatient unit.

Terra described the story by saying "She was involuntarily admitted. She was not believed if she did disclose that story. And she was sent back home to her abuser." The phrase that Terra used describes how the husband in this situation was treated as an unquestionably credible source of information. He was therefore able to manipulate the mental health system. His word had devastating consequences for the woman who was not believed, got multiple psychiatric diagnoses as a result, and eventually ended up surrendering her children to her abuser. In this case, the diagnoses served as a tool to discredit her. They were given the power to discredit her because of the patriarchal system that is distrusting of women fleeing violence. Terra talked about another instance in long-term care where the staff were doing an investigation of sexual assault and a woman's husband was allowed to stay in the room while she was being interviewed. Terra noted, "Going in there was definitely this assumption that most likely like they hadn't experienced anything. At least not from the husband. So the husband was present the entire time." The assumption that the husband was innocent had to do with the credibility and trustworthiness afforded to him. However, the trustworthiness of men does not translate into them being provided with services when they experience trauma, as previously discussed, in 
Sarah's interview when she mentioned a frustration that she had when trying to find appropriate services for men.

\section{People who "get it"}

One common thread through the interviews that I had with mental health professionals was the way they talked about people who do and do not "get it." In my interview with Terra, she talked about the people who she worked with as people who "get it" because they come from a specific framework. She says:

They got it. I was really fortunate there in the sense that a lot of the staff, even though they were nurses and doctors, they all came from a specific framework. They also brought a kind of like common sense understanding.

She thought that one way to "get it" was to work from a specific framework based in "common sense." She also described how a lot of the people who work in long-term care are Black women who bring lived experience of oppression that allows them to do good work. She also thinks that common sense is important for doing the work because she said:

I don't think that there's anything that can prepare you for in terms of training for dealing with situations like that and being supportive. But at the same time, like I wish that more resources were made available to people in long-term care homes for sure.

This quote is interesting to me because although Terra said that she thinks some of the understanding is innate, she still thinks that workers need more resources in order to provide effective services. I think that she touched on an important point about the balance between lived 
experience and professional training in that sentence. Both can be helpful for providing services and contribute to the discourse of who "gets it".

In my interview with Pauline there was the sense that the average hospital social worker did not "get it." For example, Pauline described her supervisor as someone who was more radical than the "typical" hospital social worker. She said:

I mean, like, my supervisor is a social worker and is pretty in line with what my viewpoints are. Like I would say she she's more, I don't know what word to use, but like... radical than a lot of the other typical hospital social workers.

The comparison between Pauline's supervisor and other "typical" hospital social workers positions most hospital social workers as people who do not "get it". She also mentions the ways that her supervisor is different from other hospital social workers by describing a situation where the supervisor helped a patient avoid being sent to the emergency psych department for having suicidal ideation. She said, "She's much more willing to just like, do what's best for the client, even if it's not... [what the hospital wants]". She also speculated about what other social workers would do and said "a lot of other people would have just been like, oh, okay, well, like, I can't talk you down in five minutes. So psych emerge." And in regards to how she finds that approach she said "I feel like, yeah, going to psych emerge like, would not have been helpful, but that's what our manager would have said." About the situation she stated that it was risky for the supervisor to make that decision and talked about how decisions are often made in the interest of the hospital and not the person. She said:

Because it's like, we're covering our ass like, it was super risky for like, at the end of the day it was my supervisors' decision to be like "I trust you that you're going to go home 
and be okay. And like, we have an appointment tomorrow morning. And I trust that you're going to make it in for that." Okay. Which was super risky on her part, but in the end was the best thing for that person to put trust in them.

The thing in this excerpt that separated Pauline's supervisor from other social workers who did "not get it" were her actions to put the patient's needs above the hospital protocol. I also think an important phrase in this passage is "put trust in them." By trusting the patient, the social worker demonstrated a validation of their viewpoints and resisted epistemic violence of the hospital system that would have seen the situation differently and imposed the more powerful viewpoint onto the patient.

Sarah described people who "get it" in different terms. She discussed how where she works only a few clinicians have experience with understanding trauma because it is a workplace that is focused on mental health. When working with people who have experienced sexual violence, she talked about it is the clinicians' work experiences that determine whether or not they "get it". She said, "I mean, the few clinicians that have experience with trauma, they get it totally, but then other people, I doubt it, like, those are two different streams." She also talked about people's professional training and how that affected the way that they worked. On her mental health crisis team there were people from a number of different professions doing the same work. She described it as:

It's a very mixed bag about where people come from, what their experiences are, like the workers. So on my team, everyone is either a social worker or a nurse, so the nurses could have zero, basically, I mean, they probably wouldn't get hired. But like, if we were desperate, they just need a nursing certificate. Right? Like they just need to be an RN. So, yeah, nothing 
basically. And then social work. I mean, most people that finished social work, have some mental health [training], but I mean, they might have done all of, like, you know, you could go through social work school and do all your sort of [specialized] stream.

In Sarah's workplace it is possible for workers to have no training on how to work in the mental health sector, let alone about how to work with people who have complex experiences of trauma and sexual violence. She also described how having a little bit of knowledge can be dangerous because then doctors can dismiss people's mental health symptoms as being all about trauma, when it may not be the case. She said:

I have a friend that has struggled with, like mental health symptoms, you know, for a long time, like, since she was a teenager or whatever. And she had incidents of sexual violence, like in her like 20 s, or 30 s, or whatever. So when she, like her mental health was getting worse and worse and worse. And she felt like she really needed psychiatric treatment. And so she went to the family doctor, or whatever, and was like, "I need to be on an antidepressant". And, the doctor was like "yeah, but you've been raped. Like, so you should just go to a sexual assault center" or whatever. And she's like, "no but I need an anti-depressant. Like, I've been depressed since I was 15 . I got raped when I was 30." Right? Like, so... I mean, in some ways a little bit of knowledge is really dangerous too.

In the case of this doctor, his little bit of knowledge about trauma made the person unable to access the medication that she felt would help her. Therefore, it is important to think about what knowledge is helpful and how thinking that you "get it" could also lead to negative outcomes for the person seeking services. 
In all of the interviews the participants were generous when talking about co-workers who have done things that are harmful to people who have experienced sexual violence. For example, Terra talked about a co-worker who told her an individual had disclosed to them they were raped. However, the co-worker told Terra they thought the person did not understand what rape meant. When prompted to talk about where that comment came from Terra responded saying:

It was probably coming from a good place. But I think especially having done a little bit more research and like working on some things... It's coming from a place of like assuming that people with intellectual disabilities and developmental disabilities like truly don't understand what that means. And I think that sometimes that's a very fair assumption to make because a lot of the literature says that part of the reason why people with those diagnoses get taken advantage of and get sexually abused is because they don't know that they can say no.

In this case, Terra assumed that the clinician was "coming from a good place," and even endorsed the assumption that people with "intellectual disabilities" do not understand what rape is, saying the assumption was "very fair." To me, this is evidence of the infantilization of disabled people and contributes to their experiences not being believed or taken seriously. In my interview with Sarah, she also gave other clinicians the benefit of the doubt when I asked about people being believed or not when they disclosed experiences of sexual violence. She said:

Whether or not a person is believed isn't necessarily something that's talked about, you know what I mean? That's sort of an internal thing in a clinician, so I can't really speak for other people. But like, the evidence suggests that they're not believed, you know what I mean? So it's hard to say... 
In this case even though the "evidence suggests that they're not believed" Sarah said that she could not say for sure whether or not the clinicians believed the person. I also find it important to note that the topic of believing people is not talked about in Sarah's workplace. This suggests that there is not a lot of collaboration between clinicians and that someone's "stream" is determined on the opinion of one person and whether they are believed or not. Finally, one part of Pauline's interview sticks out for me in terms of defending the actions of clinicians. When I asked about how she resists the notion that the "person is the problem." She says:

I certainly don't think I see people in terms of their diagnosis. I mean, like, I'm pausing, because, like, that's tough with the high prevalence like be BPD in this program and, and the fact that we do work with psychiatrists.

The notion of not "seeing people in terms of their diagnosis" to me erases the person's identity, though, in my experience it is a popular idea. That particular sentence made me think of the critique of person-first language in critical disability literature. Some consider person-first language to be based in ableism because it minimizes disability from a person's identity as if it is shameful (Titchkosky, 2001). However, I see what Pauline was talking about after doing more research into BPD as a diagnosis. In order to not pathologize people's experiences of trauma, she tries not to focus on a stigmatizing diagnosis and instead works with the person in front of her. Although, she is generous with clinicians who do stigmatize people diagnosed with BPD saying that it is "tough." I think that in all of these situations the participants attempt to recognize that societal structures of power influence the work of their co-workers and themselves. In order to resist these systems of power, however, I think it is important to name them as such, and attempt to subvert the harmful ideas service providers are surrounded with. 


\section{CHAPTER 5: DISCUSSION \& IMPLICATIONS}

In this chapter, I talk about the four discourses that I have identified and analyze them based on my theoretical frameworks. I connect the discourses of being boiled down/ chalked up to an experience or diagnosis and credibility to feminist theories and anti-sanist theories about psychocentrism. Discourses of professionalism and people who "get it" are discussed using anticapitalist theories. The "streams of care" discourse is analyzed using anti-racist, anti-colonial and antisanist theories. All of the discourses are inter-related and talked about in ways that deconstruct the how they uphold or are indicative of various systems of power and oppression. Throughout this discussion, I point to the implications for social work in order to enhance practice with survivors of sexual violence.

The discourse of people being "boiled down" to one thing has to do with the pathologization of people's experiences. One of the diagnoses that was mentioned the most in the interviews I conducted was "borderline personality disorder" (BPD). This particular diagnosis has been critiqued because of its over-representation in women and for being "centrally located within gendered structures of power" (Shaw \& Proctor, 2005, p.484). Shaw and Proctor's (2005) article mentions that the women who are diagnosed with borderline personality disorder are often survivors of violence and that the diagnosis acts as a way to erase the pervasiveness of sexual violence. They state:

The central position that potential and/or actual sexual violence, abuse and harassment occupies within our culture, is effectively obscured by the psychiatric labelling of survivors. The consequences of this cannot be overstated. Social change begins with awareness: labels such as BPD play an important role in ensuring that wider society is not 
generally aware that mental health services are filled with people who are struggling with the violence, abuse and inequality that characterize our society. (p.488)

The critique of BPD is essential for understanding the interviews that I conducted. Two of the participants mentioned BPD as a particular diagnosis that stood out for them when thinking of their work within the mental health system with survivors of sexual violence. In fact, Pauline mentioned that she felt the diagnosis made individuals less likely to be believed if they do disclose experiences of sexual violence because of the stigma associated with it. This connection shows how the diagnosis of BPD acts as a patriarchal tool to dismiss gender-based violence. In particular, the article cites that $70 \%$ of people who are diagnosed with BPD have experienced childhood sexual abuse (Shaw \& Proctor, 2005). Therefore, it is especially important for understanding sexual violence and the ways that the psychiatric system treats survivors of sexual violence in a way that makes them the problem and maintains rape culture.

When discussing how people in long-term care are reduced down to their experiences if they disclose being sexually assaulted, Terra said they are treated like "they're a body not a person." I think that this is an important phrase to pick out because it mirrors the way that sexual violence is talked about. It is discussed in a way that prioritizes the physical experience of being assaulted without acknowledging the psychological and emotional reactions. It also definitely does not address the systems that reinforce and contribute to sexual violence. Therefore, when talking about sexual violence, it is important that it is politicized as being part of a larger system of patriarchy. When the focus is on systems, it allows people to be treated as whole and complex, rather than reducing them to their experiences. Furthermore, there needs to be a better understanding of sexual violence within the mental health system so that those accessing services are provided with appropriate resources. Breslow's (2019) article suggests that something 
"troubled-persons industries," including social work, can learn from Mad studies is to consider the whole person and their potential. They say "Simply conferring a diagnosis is tantamount to stripping away the human-ity of the person in favour of a psy-label straightjacket” (p.61). Therefore, the discourse of people being "boiled down" to their diagnosis is a form of dehumanization that needs to be challenged by learning from Mad studies.

Moreover, in the interviews I conducted, there was definitely the idea that mental health professionals are meant to know about sexual violence, yet there is no system in place to ensure that is actually a reality. The participants noted a lack of training from the mental health system not only about sexual violence, but also even training related to mental health services. It is concerning that people are expected to find their own resources because it provides a lack of standards, and leaves the quality of support someone receives up to chance depending on who their clinician happens to be. While there was a sense from participants that more training would be helpful to provide adequate services, the notion is also present that one can only be trained so much within a system that has fundamental flaws in the way it is set up. For example, in my interview with Pauline, she mentions that the ability to be critical in her workplace is limited by "the fact that we do work with psychiatrists." Moreover, Terra mentions that the lived experience of workers in long-term care contributes to their abilities to do good work. However, they are also devalued because of this and consequentially under-paid and under-valued as workers.

While I think that training is important to making the mental health system less harmful for survivors, I also recognize that this is only a "band-aid" approach. In reality, the bio-medical mental health system is one that upholds and reinforces systems of oppression, including sexism. In order to make it safe for survivors, I believe that the whole mental health system needs to undergo a reformation that makes it center the needs of people and social justice instead of social 
control and neuro-conformity. Then the mental health system would no longer be dominated by a bio-medical focus. The discourse of increased professionalization and increased training also upholds systems of capitalism that place value on formal education instead of lived experience. I therefore suggest that any training needs to come from advocacy groups and people personally impacted by the psycho-centric mental health system and sexual violence. Moreover, people with lived experience should be seen as the experts in their own lives and needs.

Furthermore, the fact that there are different "streams" of care is something that came up multiple times in the interviews. One particularly troubling aspect of the "streams" was that Pauline mentioned that people in her workplace need to meet certain criteria before being able to access the "trauma stream." Therefore, people are put into the mental health stream in order to "stabilize" them to be able to deal with the trauma that they have experienced. However, Sarah mentioned that when people are funneled into the wrong stream it can have devastating consequences. For example, she talked about how when people are put into mental health streams who really need trauma services, often the medications and services do not work for them and they end up being labelled "non-compliant." This creates a cycle where people never receive the services that they need because there are pre-requisites to accessing care based on compliant behaviour. In their article "I'm not bipolar, I'm traumatized: What I learned about Black womanhood from my misdiagnosis" Ashley Young discusses how trauma can mimic mental health criteria and how this influences Black women in particular. They say:

Many of us are in a heightened state of paranoia, anxiety, rage and agitation because we are forced to live in a world where our bodies are policed, violated and then discarded. I am not saying this to discredit what could be considered legitimate diagnoses of Black 
people. I'm saying this because if we are being honest about mental illness, most of Black America would meet much of the criteria due to our trauma. (para. 21)

It is important to think about how trauma affects mental health because mental health and marginalization are interrelated. For example, psychiatrized people experience discrimination in the criminal justice system (Canadian Mental Health Association Ontario, 2014, May). Racialized people are also over-criminalized in Canada. For example, in their (2014) book, Chan and Chunn state that "race intersects with nationality, immigration, and class to produce 'undesirable' subjects of criminalization, illegalization, and exclusion” (p.117). Therefore, not providing people access to trauma services until they meet behavioural pre-requisites puts people at risk for further trauma and violence because of the increased level of policing that results when there is an intersection of racialization and psychiatrization.

The separation of services into streams signals to the systemic separation of the body, mind, and experiences. Hodge, Limb and Cross (2009) argue that mental health services are often ineffective for Native Americans and at worse they are "a vehicle for Western colonization" (p.211). They argue that "health and well-being are the result of the complex interplay among our spirituality, physical status, cognitive and emotional processes, and environments" (p.215). Therefore, the separation into "streams" is not only ineffective, but also an act of colonization and epistemic violence. Epistemic violence is when ways of seeing the world are devalued or seen as illegitimate and the term comes from postcolonial scholarship (Liegghio, 2013). Since the separation of services makes access difficult and less effective, it acts as a form of gas lighting people who access services but who are not better off because of it. If the mind, body, spirit, and environment are all connected, then treating them separately will never result in positive outcomes. This is especially true for Indigenous people, who have higher 
rates of suicide than the general population, resulting from the trauma brought on by ongoing colonization (Baker, Goodman \& DeBeck, 2017).

A significant factor in what stream of care people access is that there is a two-tiered system of services that people pay a lot of money for or not. Money was an access issue that came up in the interviews I conducted. Capitalism is clearly intertwined with the mental health system and affects the type of care that people can access. For example, a lot of public services have long wait times, and Sarah cited this as being a barrier that she sees in her practice with individuals in rural communities. Pauline also mentioned that marginalized people are less comfortable accessing services in the hospital she works at because it is a larger institution with a history of oppression. However, community mental health services are often underfunded (CMHA, 2017, October, 19). Therefore, there are barriers based on class and race for accessing services. This was seen in my study as well, because all of the participants who are service providers were white-passing women. The lack of representation in this study is further discussed in the "limitations" section.

In terms of credibility, multiple times men were cited as being trustworthy subjects. In both instances, they were also the husbands of the women accessing services. The prioritizing of men's perspectives calls into question not only patriarchy, but also the institution of marriage. For example, Terra spoke about a woman's husband being unquestioned when there was suspicion that she was being sexually assaulted and was allowed in the room while she was being interviewed. Him being seen as an unquestioned and trustworthy subject is not surprising when I think about the history of sexual assault legislation and that marital rape was only made illegal in Canada in 1983 (Koshan, Randall \& Sheehy, 2017). The newness of marital rape laws shows that the institution of marriage is seen as a protective factor and how this assumption can make it 
more difficult for people experiencing abusive marriages to be believed or deemed credible.

When paying attention to discourses of credibility in the interviews, something that came up more than once was that behaviour and diagnosis influenced whether or not someone was believed, listened to, and whether they internalized sanist interpretations of themselves. Shaw and Proctor's (2005) article addresses this issue when they talk about how BPD diagnosis is based on the assumption that someone's reactions to oppression are inappropriate. They say "both anger and fear of abandonment can be - and frequently are - judged to be inappropriate, as opposed to being understandable in the context of a person's history of being violated or abandoned" (p.485). Therefore, in order to focus on social justice-based approaches it is important to contextualize a person's behaviour and consider that it may be a normal reaction to an unfair system, especially when it comes to racialized and Indigenous communities. Part of resisting sanism is also recognizing that people have a wide array of reactions to situations and that categorizing some reactions as "deviant" and "needing to be fixed" is a form of violence that upholds systems of power.

Finally, when thinking through the discourse of who "gets it" a lot of variables were discussed in the interviews. All of the social workers I interviewed expressed opinions about the frameworks that they work from, sometimes described as feminist, critical, or anti-oppressive. In making this distinction they distanced themselves from those who "don't get it," or, as one participant described the "typical hospital social worker." Hence, part of "who gets it" has to do with perspective and training. Though one participant also mentioned social location as being a factor in who "gets it" stating that racialized workers "got it" because they were more likely to experience the oppressions that service users did and could therefore understand in a different way. I think that in this section it is important to think about what stake people hold, including 
myself, in being someone who "gets it." Does it make people more likely to do good work if they "get it"? Or is it a label that someone can claim because they do some things less harmful than other social workers? I also wonder how the idea of "getting it" is related to capitalism and the ability to be considered a professional or "expert." How does the focus on "getting it" undermine learning?

As a student, I think these are incredibly important questions to think about in order to practice reflexivity. When I think about my own practice and research, I believe it is important to recognize that nobody ever fully "gets it" because learning is lifelong. There are some things that I will never experience or fully understand because of my positioning as a white woman in profession that is dominated by people like me. This also applies to the white-passing participants that I interviewed. However, part of doing critical analysis is trying to do less harm and work on decolonizing academic spaces to the extent that one can in limited institutions. Therefore, I point to critical scholarship in order to guide my understanding and, hopefully, provide a meaningful perspective.

\section{Study Limitations}

While the information given by participants can be indicative of larger systems, it is important to point out that these are personal experiences and do not "prove" trends in the biomedical mental health system because of the qualitative nature of the research. The research is, however, meant to highlight the experiences of the participants and deconstruct medical discourses as they relate to mental health and sexual violence. Moreover, the research cannot be extended to the entire mental health system, because although the participants have a wide range of experiences, they have not had experience in every field of work related to the vast bio- 
medical mental health system. Their experiences do not represent that of all social workers in this system as all of the participants were white-passing women. As a white woman myself, I recognize that the research will have a bias towards whiteness that must be questioned when taking into consideration the experiences of interviewing, analyzing the interviews, and what is shared or considered. I see how my study has reproduced mental health institutions' centering of whiteness and it is one of the major limitations of this paper. However, this provides me with an opportunity to reflect on the way that power influences the people who are able to access services including providing input into research studies.

My study was a practice in "studying up" (Deliovsky, 2017). Studying up involves studying people and institutions that hold power (2017). In the case of my research, studying up takes the responsibility off survivors to validate their experiences through self-disclosure, which is done frequently in the literature. Though it was unintentional, the practice of studying whitepassing service providers also takes the responsibility off of racialized service providers to do extra work and have to explain their lived experiences to a white woman researcher. However, I do think that people of colour's experiences are important to listen to and suggest that their perspectives on the mental health system and sexual violence could be an area to be studied in the future to get a more robust picture of the issues.

In ending and based on the findings of this MRP, I would argue that the mental health system is causing people harm. In order to imagine new possibilities for social work, it is important to challenge powerful institutions and value marginalized perspectives. The shift away from powerful ways of knowing is a way to resist epistemic violence. Sometimes harm is not readily apparent. For example, the ways in which service providers who "mean well" subtly reinforce psycho-centrism. Other times, harm is apparent in that psychiatrized people are 
prescribed medications for years that negatively impact their health. However, no matter the amount of harm done, it is important to question the systems that social workers operate from in order to truly support an agenda of social justice. I work from a perspective that is concerned with challenging the status quo. In this paper I hope that I could provide an alternative perspective from which to see the bio-medical mental health system and the ways it operates to oppress survivors of sexual violence. 


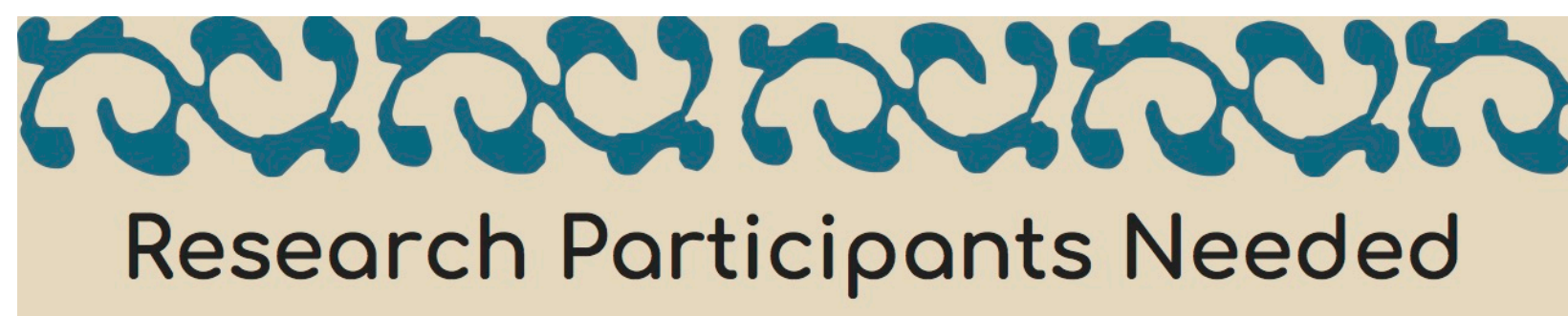

Have you worked or been a placement student in a mental health agency that operates from a bio-medical perspective*?

\section{AND}

Have experienced a disclosure of sexual violence in your workplace?

If so you are eligible to participate!

*Bio-medical perspective is one that focuses on "mental illness" as brain disease. Agencies that often use this perspective include hospitals, shelters, group homes and Assertive Community Treatment (ACT) Teams

WHAT: Study aimed at critically analyzing how sexual violence is discussed within the bio-medical mental health system to challenge current practices

You will be asked to participate in a 2-hour maximum one-time in-person interview in

a location of your choosing to discuss your professional experience working with survivors of sexual violence.

Interviews will be audio-recorded for transcription purposes.

In appreciation of your time, you will receive a \$10 visa gift card

If you are interested in participating in this study, or would like more information, please contact: Julia Getchell, MSW Student jgetchell@ryerson.ca

This study is being conducted in partial fulfillment of a Master of Social Work degree.

Research supervisor Samantha Wehbi, professor in the school of social work can be contacted at swehbi@ryerson.ca
Participation is completely voluntary and you have the right to withdraw at any time.

This study has been reviewed by the Ryerson Ethics Board

File Number: 2018-447

\section{Ryerson University}




\section{APPENDIX - B}

Hello,

My name is Julia Getchell. I am a student at Ryerson University in the school of social work. I am contacting you to see if you might be interested in participating in a research study.

This research is being done as part of my Masters project and my supervisor's name is Dr. Samantha Wehbi, professor in the school of social work at Ryerson (swehbi@ryerson.ca).

The purpose of the research is to explore the ways sexual violence is discussed within the biomedical mental health system in Canada.

Sexual violence is a broad term that describes any violence, physical or psychological, carried out through sexual means or by targeting sexuality. Sexual violence is understood in this project to not be a series of unconnected incidents, but as systems of violent expressions of power.

The bio-medical understanding of mental health is one that focuses on "mental illness" as brain diseases and emphasizes taking medication to target these assumed brain abnormalities. Organizations that often work from this perspective include, but are not limited to, hospitals, group homes, Assertive Community Treatment (ACT) Teams, and shelters.

It is important to understand the ways that the ways sexual violence is discussed in these settings because survivors of sexual violence are most likely to encounter the mental health system before any other professional services, including sexual assault centres, medical systems, or legal systems. Moreover, past research has suggested that bio-medical mental health services are often harmful to survivors of sexual violence.

To participate you need to be a past or present social worker, social service worker, or other mental health professional who has worked in the following areas:

Hospital

Group Home

Assertive Community Treatment (ACT) Team

Shelter

Another mental health agency that works from a bio-medical model

\section{AND}

Have had professional contact with at least one survivor of sexual violence.

Students who have had professional placements in one of the above settings AND during that time had contact with a least one survivor of sexual violence in that placement are also eligible to take place in the study

Volunteers, other than professional placement students, are not eligible to partake in the study. People who do not consider their past/present workplaces to be working from a bio-medical understanding of mental health are not eligible for this study. If the participant has not had 
contact with a survivor of sexual violence in their above professional context they are ineligible for this study.

If you agree to volunteer, you will be asked to complete an in-person interview. Your participation will involve a one-time interview, lasting no more than 2 hours.

In appreciation of your time, you will receive a $\$ 10$ visa gift card.

Your participation is completely voluntary and if you choose not to participate it will not impact our relationship or your relationship with Ryerson University.

The research has been reviewed and approved by the Ryerson University Research Ethics Board. The research file number is 2018-447.

If you are interested in more information about the study or would like to volunteer, please reply to this email.

Sincerely,

Julia Getchell, MSW Student 


\section{APPENDIX - C}

\section{Questions}

1. Can you tell me about a time, or multiple instances, when someone accessing mental health services from your agency disclosed that they were a survivor of sexual violence?

2. How did you respond to this disclosure?

- How would you have liked to respond?

- What considerations or constraints affected your response?

3. Was this experience of disclosure discussed within your agency?

- If yes, what was that experience like for you?

- Did feel supported by your co-workers or agency? Why/why not?

4. Were there any protocols, supports, or referral information provided to you by your agency about how to handle these disclosures beforehand?

- If so what?

5. How well do you think you were prepared in advance by your agency to provide services to survivors of sexual violence?

- How do you think this could be improved?

6. Have you ever received training on how to support survivors of sexual violence from outside of your agency?

- If so, where?

- Did the information given to you differ from that received at your agency?

- If so, how?

- What do you wish you could know more about to better support survivors of sexual violence? 


\section{$\begin{array}{ll}\text { Research } \\ \text { Ryerson } & \text { Ethics Board }\end{array}$}

To: Julia Getchell

Social Work

Re: REB 2018-447: Mental Health Systems and Sexual Violence: A Critical Discourse Analysis

Date: January 18, 2019

Dear Julia Getchell,

The review of your protocol REB File REB 2018-447 is now complete. The project has been approved for a one year period. Please note that before proceeding with your project, compliance with other required University approvals/certifications, institutional requirements, or governmental authorizations may be required.

This approval may be extended after one year upon request. Please be advised that if the project is not renewed, approval will expire and no more research involving humans may take place. If this is a funded project, access to research funds may also be affected.

Please note that REB approval policies require that you adhere strictly to the protocol as last reviewed by the REB and that any modifications must be approved by the Board before they can be implemented. Adverse or unexpected events must be reported to the REB as soon as possible with an indication from the Principal Investigator as to how, in the view of the Principal Investigator, these events affect the continuation of the protocol.

Finally, if research subjects are in the care of a health facility, at a school, or other institution or community organization, it is the responsibility of the Principal Investigator to ensure that the ethical guidelines and approvals of those facilities or institutions are obtained and filed with the REB prior to the initiation of any research.

Please quote your REB file number (REB 2018-447) on future correspondence.

Congratulations and best of luck in conducting your research.

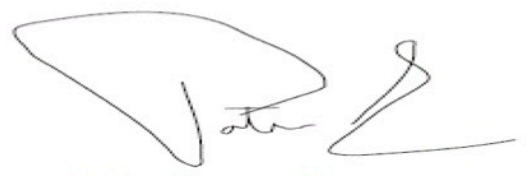

Dr. Patrizia Albanese, $\mathrm{PhD}$

Chair, Ryerson University Research Ethics Board

The Following protocol attachments have been reviewed and approved. 
- REB - Flyer - Julia Getchell.pdf (submitted on: 25 Nov 2018)

- REB - References - Julia Getchell .docx (submitted on: 25 Nov 2018)

- REB - Interview Guide - Julia Getchell .docx (submitted on: 25 Nov 2018)

- REB - Email Script - Julia Getchell .docx (submitted on: 25 Nov 2018)

- REB - Comments to Chair - Julia Getchell .docx (submitted on: 11 Jan 2019)

- REB - Flyer - Julia Getchell - V2 .pdf (submitted on: 11 Jan 2019)

- REB - Email Script - Julia Getchell - V2 .docx (submitted on: 11 Jan 2019)

- REB - Facebook Post - Julia Getchell .docx (submitted on: 11 Jan 2019)

- REB - Consent Form - Julia Getchell - V2 .docx (submitted on: 11 Jan 2019)

- REB - Consent Form - Julia Getchell .docx (submitted on: 11 Jan 2019)

If any changes are made to the attached document throughout the course of the research, an amendment MUST be submitted to, and subsequently approved by the REB. 


\section{REFERENCE LIST}

Ahrens, C.E., Stansell, J., Jennings, A. (2010). To tell or not to tell: The impact of disclosure on sexual assault survivors' recovery. Violence and Victims, 25(5), 631-648. doi: 10.1891/0886-6708.25.5.631.

Attfield, R. (2001). To do no harm? The precautionary principle and moral values. Reason in Practice, 1(3), 11-20. https://doi-org.ezproxy.lib.ryerson.ca/10.5840/pom2001133.

Audi, R. (2003). Epistemology: A contemporary introduction to the theory of knowledge. Routledge: New York.

Baker, B., Goodman, A., DeBeck, K. (2017). Reclaiming Indigenous identities: Culture as strength against suicide among indigenous youth in Canada. Canadian Journal of Public Health, 108(2), 208-210. doi:10.17269/CJPH.108.5754.

Breslow, K.B. (2019). Perspectives in AE: What troubled persons industry professionals can learn from Mad Studies. New Horizons in Adult Education \& Human Resource Development, 31(1), 59-64. https://doi-org.ezproxy.lib.ryerson.ca/10.1002/nha3.20240.

Bryant-Davis, T., Ulman, S.E., Tsong, Y., Tillman, S., Smith, K. (2010). Struggling to survive: Sexual assault, poverty, and mental health outcomes of African American women. American Journal of Orthopsychiatry, 80(1), 61-70. doi: 10.1111/j.1939-0025.2010. 01007. x.

Campbell, R., Raja, S. (1999). Secondary victimization of rape victims: Insights from mental health professionals who treat survivors. Violence and Victims, 14(3), 261-275. doi:10.1891/0886-6708.14.3.261. 
Campbell, R., Raja, S., Grining, P.L. (1999). Training mental health professionals on violence against women. Journal of Interpersonal Violence, 14(10), 1003-1013. https://doiorg.ezproxy.lib.ryerson.ca/10.1177/088626099014010001.

Canadian Mental Health Association. (2017, October, 19). CMHA urges for better funding. Retrieved from: https://cmha.ca/cmha-urges-for-better-funding.

Canadian Mental Health Association Ontario. (May 2014). Advancing equity in Ontario: Understanding key concepts. Retrieved from: http://ontario.cmha.ca/wpcontent/uploads/2016/07/Advancing-Equity-In-Mental-Health-Final1.pdf.

Chan, W., Chunn, D. (2014). Racialization, crime, and criminal justice in Canada. University of Toronto Press.

Deacon, B.J. (2013). The biomedical model of mental disorder: A critical analysis of its validity, utility, and effects on psychotherapy research. Clinical Psychology Review, 33, 846861. doi: 10.1016/j.cpr.2012.09.007.

Deliovsky, K. (2017). Whiteness in the qualitative research setting: Critical skepticism, radical reflexivity and anti-racist feminism. Journal of Critical Race Inquiry, 4(1), 1-24. doi:10.24908/jcri.v4i1.6369.

Diamond, S. (2013). Chapter 4: What makes us a community? Reflections on building solidarity in anti-sanist praxis. In B. LeFrancois, R. Menzies, \& G. Reaume (Ed.s.), Mad matters: A critical reader in Canadian mad studies. Toronto, Ontario: Canadian Scholars' Press, p. 64-77.

Eidse, J. (2018, June, 13). On getting a mental health diagnosis. [Blog Post]. Retreived from: https://itsnotjustyou.ca/2018/06/13/mental-health-diagnosis/. 
Eisenberg, M.E., Lust, K.A., Hannan, P.J., Porta, C. (2016). Campus sexual violence resources and emotional health of college women who have experienced sexual assault. Violence and Victims, 31(2), 274-284. doi: 10.1891/0886-6708.VV-D-14-00049.

Gerdes, K. (2018). Trauma, trigger warnings, and the rhetoric of sensitivity. Rhetoric Society Quarterly, 49(1), 3-24. doi: 10.1080/02773945.2018.1479767.

Gomez, J.M., Freyd, J.J. (2017). High betrayal child sexual abuse and hallucinations: A test of an indirect effect of disassociation. Journal of Childhood Sexual Abuse, 26(5), 507-518. doi:10.1080/10538712.2017.1310776.

Greco, D., Dawgert, S. (2007). Poverty and sexual violence: Building prevention and intervention responses. Retrieved from: https://www.pcar.org/sites/default/files/pagespdf/poverty_and_sexual_violence.pdf.

Grey, M., Plath D., S. Webb. (2009). Evidence-based social work: a critical stance. London: Routledge, 51-73.

Hodge, D. R., Limb, G. E., Cross, T. L. (2009). Moving from colonization toward balance and harmony: A native american perspective on wellness. Social Work, 54(3), 211-219. doi: 10.1093/sw/54.3.211.

Holtz, P., Odağ, Ö. (2018) Popper was not a positivist: Why critical rationalism could be an epistemology for qualitative as well as quantitative social scientific research. Qualitative Research in Psychology,1(1), 1-24. doi: 10.1080/14780887.2018.1447622.

Hsu, S. (2019). Fanon and the new paraphilias: Towards a trans of color critique of the DSM-V. Journal of Medical Humanities, 40(1), 53-68. doi: 10.1007/s10912-018-9531-3.

Hunter, M. (2002). Rethinking epistemology, methodology, and racism: or, is White sociology really dead? Race \& Society, 119-138. doi: 10.1016/j.racsoc.2004.01.002. 
Jackson, M.A., Valentine, S.E., Woodward, E.N., Pantalone, D.W. (2017). Secondary victimization of sexual minority men following disclosure of sexual assault: "Victimizing me all over again...”. Sex Res Soc Policy, 14, 275-288. doi: 10.1007/s13178-016-0249-6.

Koshan, J., Randall, M., Sheehy, E. (2017, October, 28). Marital rape myths have no place in Canadian law. The Globe and Mail. Retrieved from: https://www.theglobeandmail.com /opinion/marital-rape-myths-have-no-place-in-canadian-law/article36749822/.

Liegghio, M. (2013) Chapter 8: A Denial of Being: Psychiatrization as Epistemic Violence. In B. LeFrancois, R. Menzies, \& G. Reaume (Ed.s.), Mad matters: A critical reader in Canadian mad studies. Toronto, Ontario: Canadian Scholars' Press, p.122-129.

Meerai, S., Abdillahi, I., Poole, J. (2016). An Introduction to anti-black sanism. Intersectionalities: A Global Journal of Social Work Analysis, Research, Policy, and Practice, 5(3), 18-35. Retrieved from: https://journals.library.mun.ca/ojs/index.php /IJ/article/view/1682.

Moses, T. (2011). Adolescents' commitment to continuing psychotropic medication: A preliminary investigation of considerations, contradictions, and correlates. Child Psychiatry \& Human Development, 42, 93-117. doi:10.1007/s10578-010-0209-y.

National Institute of Mental Health (February, 2016). Schizophrenia. Retrieved from: https://www.nimh.nih.gov/health/topics/schizophrenia/index.shtml

Neuman, W.L. (2006). The meanings of methodology. In Social research methods: Quantitative and quantitative approaches (6th ed.), (pp. 79-104). Boston: Pearson Education Inc.

Patterson, D., Greeson, M., Campbell, R. (2009). Understanding rape survivors' decisions not to seek help from formal social systems. Health and Social Work, 34(2), 127-136. doi:10.1093/hsw/34.2.127. 
Poole, J. (2011). Behind the Rhetoric: Mental Health Recovery in Ontario. Winnipeg, Manitoba: Fernwood.

Rimke, H. (2016). Introduction - Mental and emotional distress as a social justice issue: Beyond psychocentrism. Studies in Social Justice, 10(1), 4-17. doi:10.26522/ssj.v10i1.1407.

Rodino-Colocino, M. (2018). Me too, \#MeToo: Countering cruelty with empathy. Communication and critical/cultural studies, 15(1), 96-100. https://doi.org/ 10.1080/14791420.2018.1435083.

Shaw, C., Proctor, G. (2005). I. Women at the margins: A critique of the diagnosis of borderline personality disorder. Feminism \& Psychology, 15(4), 483-490. https://doi.org/10.1177 /0959-353505057620.

Sigurvinsdottir, R., Ullman, S.E. (2016). Sexual orientation, race, and trauma as predictors of sexual assault recovery. J Fam Viol, 31, 913-921. doi: 10.1007/s10896-015-9793-8.

Simmel, C., Postmus, J.L., Lee, I. (2016). Revictimized adult women: Perceptions of mental health functioning and associated services. J Fam Viol, 31, 679-688. doi: 10.1007/ s10896-015-9796-5.

Starzynski, L.L., Ullman, S.E. (2014). Correlates of perceived helpfulness of mental health professionals following disclosure of sexual assault. Violence Against Women, 20(1), 74-94. doi: 10.1177/1077801213520575.

Temple, J.R., Weston, R., Rodriguez, B.F., Marshall, L.L (2007). Differing effects of partner and non-partner sexual assault on women's mental health. Violence Against Women, 13(3), 285-297. doi: 10.1177/1077801206206297473. 
Titchkosky, T. (2001). Disability: A rose by any other name? "people-first" language in Canadian society. The Canadian Review of Sociology and Anthropology, 38(2), 125-140. doi:10.1111/j.1755-618X.2001.tb00967.x.

Williams, M. (2001). Problems of knowledge: A critical introduction to epistemology. Oxford: Oxford University Press, 1-12.

Williamson, J., Serna, K. (2018). Reconsidering forces labels: Outcomes of sexual assault survivors versus victims (and those who choose neither). Violence Against Women, 24(6). 668-683. doi:10.1177/1077801217711268.

Wodak, R., Meyer, M. (2009). Methods of critical discourse analysis. SAGE Publications Ltd: London.

Young, A. (2018, May, 5). I'm not bipolar, I'm just traumatized: What I learned about Black womanhood from my misdiagnosis. Black Youth Project. Retrieved from: https://blackyouthproject.com/im-not-bipolar-im-just-traumatized-what-i-learned-aboutblack-womanhood-from-my-misdiagnosis/. 